\title{
ASSESSMENT OF THE INFLUENCE OF UTERINE APPENDAGES TORSION ON THEIR PATHOMORPHOLOGICAL CHANGES IN THE EXPERIMENT
}

DOl: 10.36740/WLek202108117

\author{
Viktor S. Konoplitskyi, Yurii Ye. Korobko \\ NATIONAL PIROGOV MEMORIAL MEDICAL UNIVERSITY, VINNYTSIA, UKRAINE
}

\begin{abstract}
The aim: The study of pathomorphological changes in uterine appendages during torsion of different duration and after their detorsion in the experiment on rats. Materials and methods: Experimental studies were performed on the basis of vivarium in the conditions of chronic experiment on 48 females of outbred white rats weighing $200.0 \pm 20.0$ grams. The essence of the experimental model is that the female rats, under the ketamine's anesthesia at the rate of $1-2 \mathrm{mg} / \mathrm{kg}$ of the drug, conduct a right-sided ovary twist at $720^{\circ}$ in the projection of the oviduct with fixation of the organs with an external clip of indifferent metal.

Results: After ovarian detorsion, until 72 hours after its torsion, reliable reversible restoration of the structural components of the ovary is determined as a positive consequence of the effect of the correction factor (detorsion).

Conclusions: The data obtained in the experiment showed that there was a discrepancy between the macroscopic features of the twisted uterine appendages and the microscopic changes in their morphological examination. Despite the presence of external signs of necrosis in the tissue of the uterine appendages, after the detorsion and the restoration of blood flow in them, studies have shown the possibility of performing organ-saving surgical operations in the torsion of the uterine appendages.
\end{abstract}

KEY WORDS: ovary, rats, hemodynamic disorders, experiment

Wiad Lek. 2021;74(8):1876-1884

\section{INTRODUCTION}

Torsion of uterine appendages (UA) (ovaries) are 2-17\% of all acute gynecological pathology in adulthood, or in 4.9 cases per 100,000 patients aged 1 to 20 years, which is about $3 \%$ of the total number of acute gynecological pathology in girls $[1-4]$.

According to many researchers, in the formation of PM torsion there are certain risk groups: anatomical congenital and acquired malformations (long mesosalpinx, tubal abnormalities, hemo- or hydrosalpinx, Morgania hydatids, etc.); physiological disorders (abnormal peristalsis, spasm or tubular hypermobility, impaired intestinal peristalsis; hemodynamic disorders (venous stasis in the mesosalpinx); sudden changes in body position (Sellheim theory); previous trauma, disease or surgery on the pelvic organs; pregnant uterus [5].

In the literature, for the most part, there is evidence of UA torsion, with the presence of volumetric formation in the ovary, which causes the ovary to become asymmetrical and can rotate around the axis in body movements. In girls, the tumors are freely in the abdominal cavity, quite mobile, due to in some cases the ovary is twisted at the attachment site - the cervix of the ovary. There is an anatomical cervix, which consists of the blood, lymphatic vessels and nerves, the proper ovarian ligament, the broad and suspensorium ovarii ligaments, and the surgical cervix, to which the uterine tube also belongs. After torsion of the uterine ap- pendages, blood supply to the organ is sharply broken, its edema, hemorrhage and then necrosis occur. Determine the full $\left(360^{\circ}\right.$ and $\left.>\right)$ and partial $\left(<360^{\circ}\right)$ torsion of UA.

Factors of UA damage during perversion are ischemia, hemorrhage, increase in the number of free radicals, inflammation, stress phenomena in ischemic ovarian tissue, impaired vascular regulation after trauma and hypoxia [6]. To date, there is no consensus on the choice of type of surgical intervention in cases with UA torsion, mainly due to the difficulty of assessing organ blood flow, even with ultrasound and laparoscopy $[7,8]$. Treatment of twisted UA is surgical: after assessment of the degree of organ's ischemia perform a detorsion or removal of the ovary [1]. This tactic is aimed primarily at preventing the development of UA necrosis and the development of peritonitis. Some researchers believe that the excision of the surgical cervix should be performed without prior detorsion, to prevent the migration of blood clots into the common bloodstream $[9,10]$. However, in recent years, there have been increasing reports of the feasibility of a organ-saving treatment in cases with torsion of UA, in which the authors argue that visual features do not always correspond to the degree of morphological features of necrosis, and this did not always require adnexectomy [11-13]. Taking into account the existing discrepancy between visual features and morphological changes in UA after torsion, it is advisable direction in the study of this problem is to determine the 


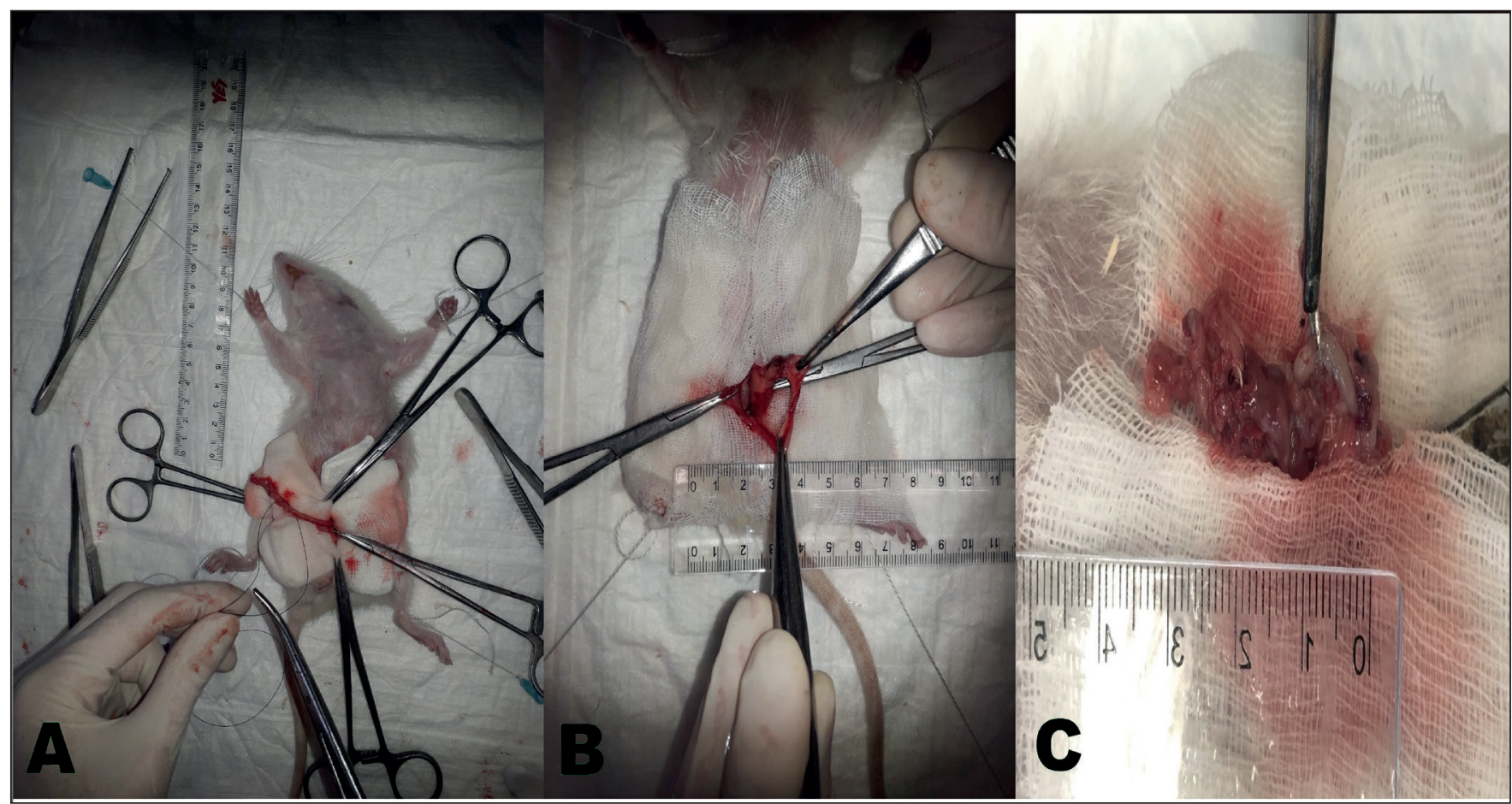

Fig. 1. The first stage of the experiment. A - evacuation into the wound of the right horn of the uterus with appendages; $B$ - determination of torsion's place of the uterine appendages; $C$ - fixation of torsion's place of the uterine appendages with a metal clip in a certain place.

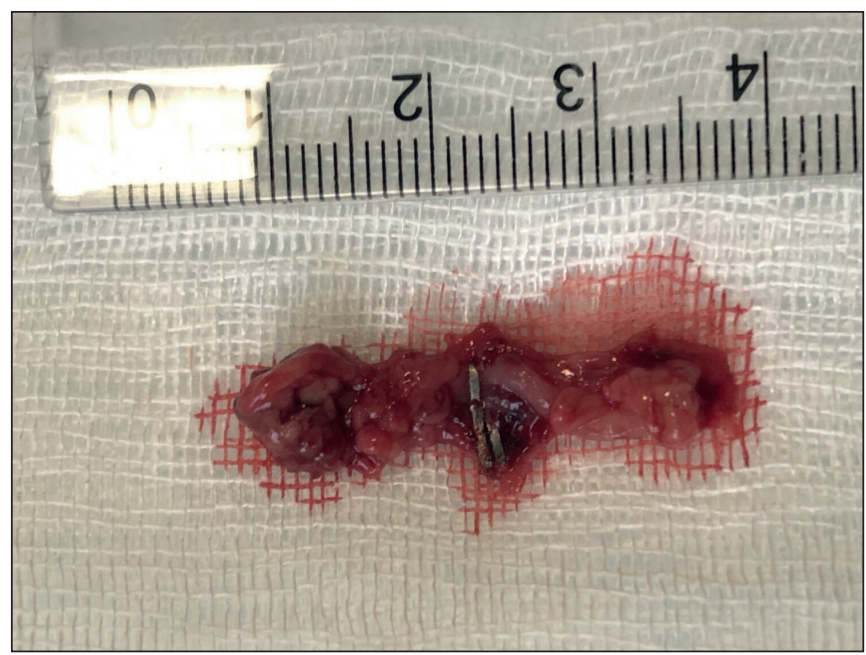

Fig. 2. Right appendages of the uterus within 24 hours after the formation of the model of pervert (macrophoto): 1 - swelling of the right horn of the uterus; 2 - hyperemia and edema of the oviduct and ovary.

structure of the ovary at different terms of torsion and after the detorsion of organ's cervix. Due to the fact that in the structure of ovaries in white rats are close to the structure of the ovaries of the humans, some extrapolation of the studies results is possible in determining the possible treatment tactics.

\section{THE AIM}

The study of pathomorphological changes in uterine appendages during torsion of different duration and after their detorsion in the experiment on rats.

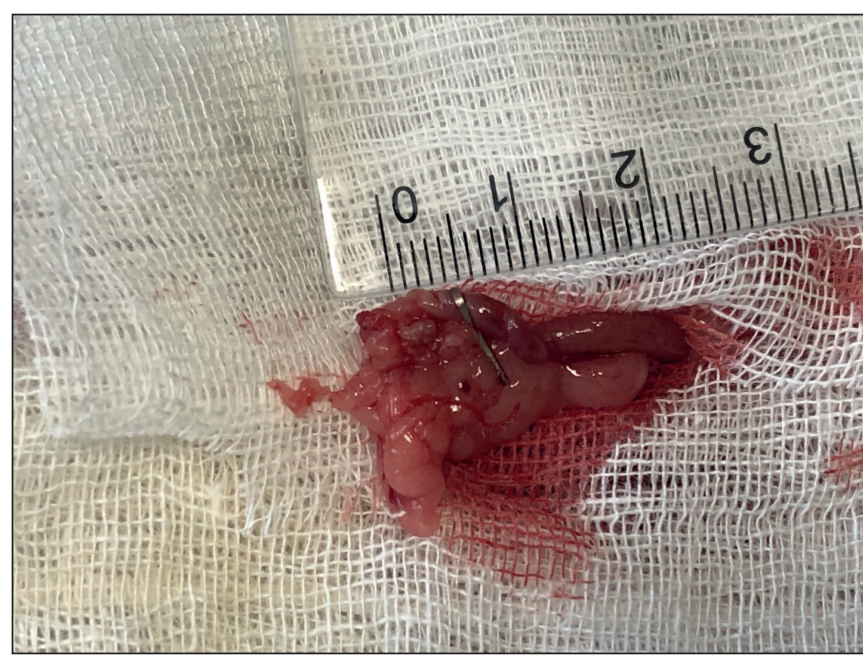

Fig. 3. Right appendages of the uterus within 48 hours after the formation of the torsion model (macrophoto): 1 - single sections of venous stasis in the vessels of the right mesovarium.

\section{MATERIALS AND METHODS}

Experimental studies were performed on the basis of vivarium in the conditions of chronic experiment on 48 females of outbred white rats weighing $200.0 \pm 20.0$ grams. The choice of experimental animals was due to the fact that in this species of mammals patterns of the ovarian-menstrual cycle are closest to the human. Also, unlike other animals, these rats have spontaneous ovulation.

The experimental study was carried out in accordance with the provisions of the «European Convention for the Protection of Vertebrate Animals Used for Experimental and Other Scientific Purposes» (Strasbourg, 1986). 


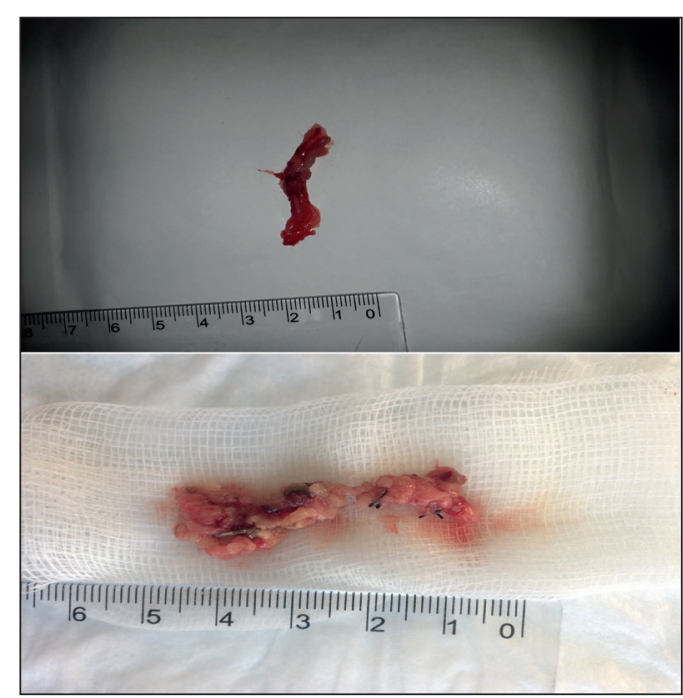

Fig. 4. Right appendages of the uterus within 72 hours after the formation of the torsion model (macrophoto): 1 - marked hyperemia and edema of the oviduct; 2 - sections of hemorrhage in the ovary; 3 -venous stasis in the vessels of the mesovarium.

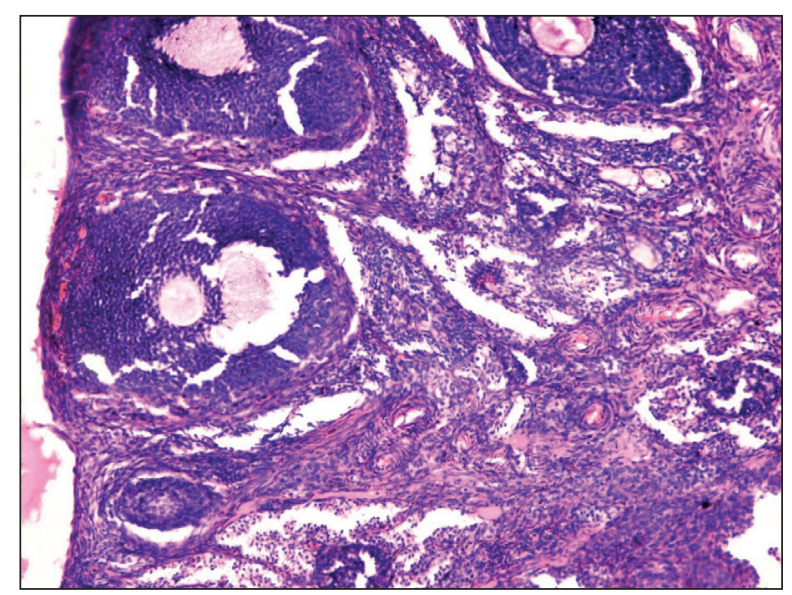

Fig. 6. Changes in the ovary of the rat after a one-day torsion: 1 - vessels of the ovarian medulla; 2 - tertiary ovarian follicles with a wide layer of follicular non-luteinized cells; 3 - primary follicle; 4 - focal hemorrhage and edema in the cortical layer. Hematoxylin and eosin staining. Magnification $\times 100$.

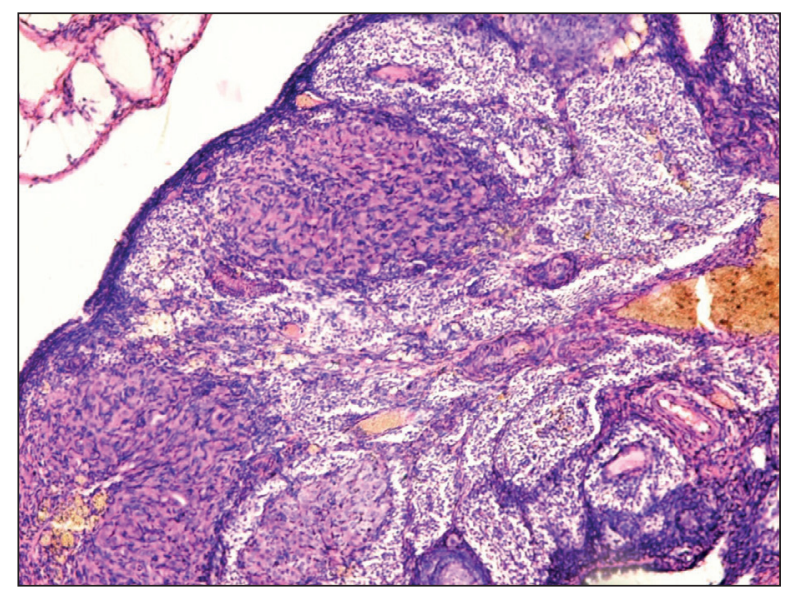

Fig. 8. Changes in the ovary of the rat after a three-day torsion: 1 - dilatation and plethora of the medulla's veins; 2 - Sertoli and Leydig cell zones; 3 - large yellow bodies with hemorrhages in them. Hematoxylin and eosin staining. Magnification $\times 100$.

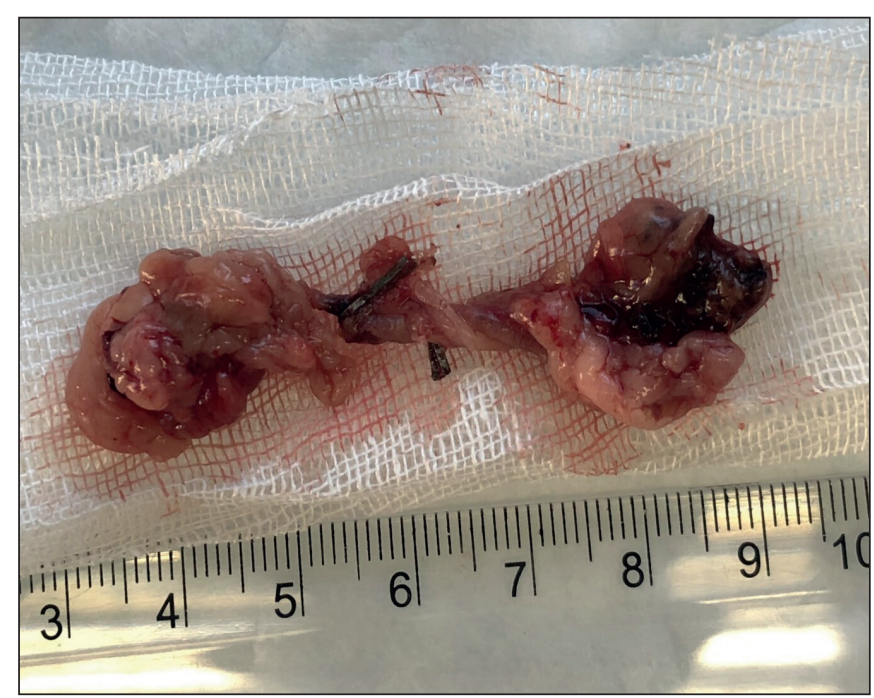

Fig. 5. Right appendages of the uterus in the period of 96 hours after the formation of the torsion model (macrophoto): 1 - marked hyperemia and edema of the oviduct; 2 - massive hemorrhages in the ovary.

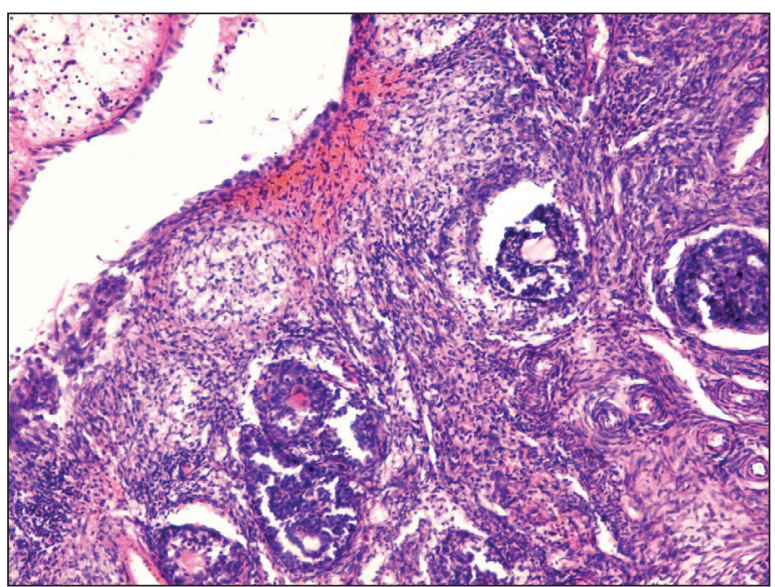

Fig. 7. Changes in the ovary of the rat after a two-day torsion: 1 - focal hemorrhage, edema in the cortical layer of the ovary; 2 - secondary follicles; 3 - optically empty vessels of the medulla; 4 - corpus luteum. Hematoxylin and eosin staining. Magnification $\times 100$.

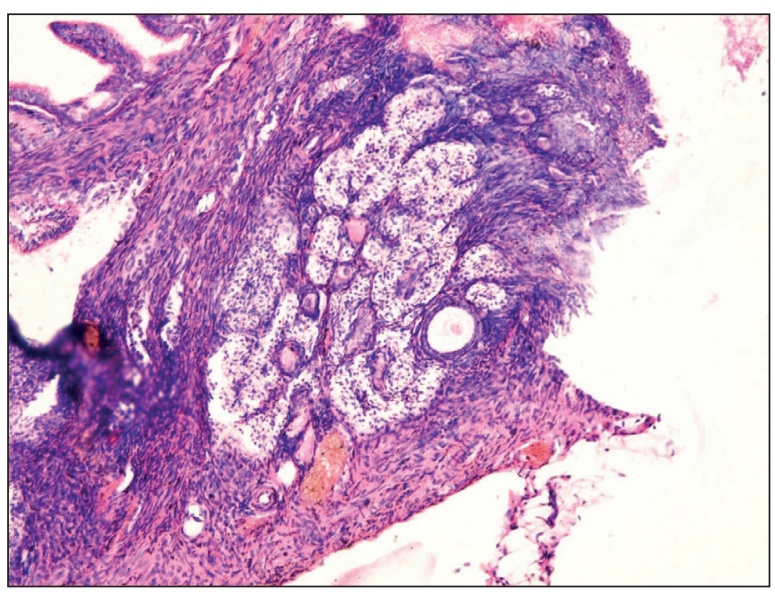

Fig. 9. Changes in the ovary of the rat after four days of torsion: 1 - dilatation and plethora of the veins of the medulla; 2 - Sertoli and Leydig cell fields; 3 - cortical layer with single primorbid follicles; 4 - connective tissue stroma of the ovary; 5 - primary follicle. Hematoxylin and eosin staining. $\times 100$. 
Table I. Design of experimental research.

\begin{tabular}{|c|c|c|c|}
\hline \multicolumn{4}{|c|}{ The first stage of the experiment. Ovarian torsion model. } \\
\hline \multicolumn{4}{|c|}{ Duration of ovarian torsion in female rats } \\
\hline$n=6$ & $\mathrm{n}=6$ & $n=6$ & $\mathrm{n}=6$ \\
\hline 1 day & 2 days & 3 days & 4 days \\
\hline \multicolumn{4}{|c|}{ Extirpation of uterine appendages for research } \\
\hline \multicolumn{4}{|c|}{ The second stage of the experiment. Ovarian detorsion after artificial pervert } \\
\hline $\mathrm{n}=6$ & $\mathrm{n}=6$ & $\mathrm{n}=6$ & $\mathrm{n}=6$ \\
\hline After 1 day & After 2 days & After 3 days & After 4 days \\
\hline \multicolumn{4}{|c|}{ Extirpation of uterine appendages for study 1 day after detrosion } \\
\hline
\end{tabular}

Table II. Quantitative evaluation of the microstructural elements of the ovary after torsion and 3 days after it's detorsion

\begin{tabular}{|c|c|c|c|c|}
\hline Indicators & Control & After torsion & After detorsion & $\begin{array}{l}\mathbf{p}_{1} \\
\mathbf{p}_{2}\end{array}$ \\
\hline $\begin{array}{l}\text { The thickness of the single-layer epithelium } \\
\text { covering the ovary, } \mu \mathrm{m}\end{array}$ & $8,22 \pm 0,11$ & $7,84 \pm 0,1$ & $9,68 \pm 0,22$ & $\begin{array}{l}\mathrm{p}_{1}<0,05 \\
\mathrm{p}_{2}<0,05\end{array}$ \\
\hline $\begin{array}{l}\text { The thickness of the ovarian protein shell, } \\
\qquad \mu \mathrm{m}\end{array}$ & $19,18 \pm 0,41$ & $21,16 \pm 0,59$ & $17,24 \pm 0,38$ & $\begin{array}{l}\mathrm{p}_{1}<0,05 \\
\mathrm{p}_{2}<0,05\end{array}$ \\
\hline $\begin{array}{l}\text { The cross-sectional area of the ovary, } \\
\qquad \times 10^{3} \mu \mathrm{m}^{2}\end{array}$ & $9223 \pm 19,38$ & $10368 \pm 22,59$ & $8678 \pm 18,52$ & $\begin{array}{l}\mathrm{p}_{1}<0,01 \\
\mathrm{p}_{2}<0,01\end{array}$ \\
\hline The area of the cortical layer, $\times 10^{3} \mu \mathrm{m}^{2}$ & $8052 \pm 16,32$ & $8324 \pm 17,82$ & $7512 \pm 16,36$ & $\begin{array}{l}\mathrm{p}_{1}<0,01 \\
\mathrm{p}_{2}<0,01\end{array}$ \\
\hline The thickness of the cortical layer, $\mu \mathrm{m}$ & $1672 \pm 11,06$ & $1734 \pm 12,32$ & $1428 \pm 11,24$ & $\begin{array}{l}\mathrm{p}_{1}<0,05 \\
\mathrm{p}_{2}<0,01\end{array}$ \\
\hline The area of the medullary layer, $\times 10^{3} \mu \mathrm{m}^{2}$ & $2564 \pm 13,96$ & $3318 \pm 15,16$ & $2154 \pm 14,22$ & $\begin{array}{l}\mathrm{p}_{1}<0,01 \\
\mathrm{p}_{2}<0,01\end{array}$ \\
\hline The thickness of the medullary layer, $\mu \mathrm{m}$ & $9058 \pm 4,36$ & $10014 \pm 5,32$ & $8694 \pm 4,64$ & $\begin{array}{l}\mathrm{p}_{1}<0,05 \\
\mathrm{p}_{2}<0,01\end{array}$ \\
\hline $\begin{array}{l}\text { The ratio of the area of the medullary layer } \\
\text { of the ovary to the cortical }\end{array}$ & $1: 3$ & $1: 4$ & $1: 3,5$ & - \\
\hline $\begin{array}{l}\text { Diameter of blood vessels penetrating the } \\
\text { medullary substance of the ovary, } \mu \mathrm{m}\end{array}$ & $12,34 \pm 1,05$ & $8,94 \pm 0,76$ & $17,38 \pm 1,46$ & $\begin{array}{l}\mathrm{p}_{1}<0,05 \\
\mathrm{p}_{2}<0,05\end{array}$ \\
\hline
\end{tabular}

$\mathrm{p}_{1}$ - the reliability of the difference between the animals in the control group and ovarian torsion;

$\mathrm{p}_{2}$ - the reliability of the difference between animals in normal and 1 day after ovarian detorsion.

The essence of the experimental model is that the female rats, under the ketamine's anesthesia at the rate of $1-2 \mathrm{mg} / \mathrm{kg}$ of the drug, conduct a right-sided ovary twist at $720^{\circ}$ in the projection of the oviduct with fixation of the organs with an external clip of indifferent metal.

The experimental model is as follows: after shaving and wetting of the skin with a solution of antiseptic, animals previously introduced into the anesthesia, performed a lower median laparotomy 2.0-2.5 cm long. at the level of the oviduct (Fig. 1).

At the designated site of the pathological process, the uterine appendages were rotated $720^{\circ}$ relative to their longitudinal axis and fixed in a predetermined position with a metal clip.

By random selection, the animals were divided into four groups of six animals each: Group I - a torsion for 24 hours; Group II - a torsion within 48 hours; Group III a torsion within 72 hours; Group IV - a torsion for 96 hours. The control group were intact animals.
For the implementation of the first stage of the experiment, all animals in four groups under these anesthesia underwent a relaparotomy with the removal of the material and its subsequent macroscopic and morphological examination. At the second stage of the experiment, pathomorphological changes were studied after the detorsion of the UA cervix with different duration (Table I).

During the second stage of the experiment, after 1,2,3 and 4 days after the model of the uterine appendage was made, all animals were operated again (first relaparotomy). We made liquidation of the uterine appendage's torsion, which was performed by removing the metal retaining clip and making detorsion of the ovarian's cervix. The postoperative wound was sutured without drainage. Then, after 24 hours, which were allotted to restore blood supply to the ovary, all animals underwent a second relaparotomy. We evaluated the visual changes in the uterine appendages, and then removed the ovarian tissues for pathomorphological studies. 
Table III. Morphometric indices of follicles in the ovaries of different groups of experimental animals

\begin{tabular}{|c|c|c|c|c|}
\hline Indicators & Control & After torsion & $\begin{array}{c}\text { After } \\
\text { detorsion }\end{array}$ & $\begin{array}{l}\mathbf{p}_{1} \\
\mathbf{p}_{2}\end{array}$ \\
\hline Number of primordial follicles in the ovary & $\begin{array}{c}8,16 \\
\pm 0,16 \\
\end{array}$ & $\begin{array}{c}7,84 \\
\pm 0,12 \\
\end{array}$ & $\begin{array}{c}9,38 \\
\pm 0,22 \\
\end{array}$ & $\begin{array}{l}>0,05 \\
<0,05\end{array}$ \\
\hline Area of the primordial follicle, $\times 10^{3} \mu \mathrm{m}^{2}$ & $\begin{array}{r}19,39 \\
\pm 0,28\end{array}$ & $\begin{array}{r}21,16 \\
\pm 0,39\end{array}$ & $\begin{array}{r}18,24 \\
\pm 0,16\end{array}$ & $\begin{array}{l}<0,05 \\
<0,05\end{array}$ \\
\hline Diameter of the primordial follicle, $\mu \mathrm{m}$ & $\begin{array}{c}9364 \\
\pm 19,42 \\
\end{array}$ & $\begin{array}{r}10368 \\
\pm 22,59\end{array}$ & $\begin{array}{c}8678 \\
\pm 18,52 \\
\end{array}$ & $\begin{array}{l}<0,01 \\
<0,01\end{array}$ \\
\hline Number of primary follicles in the ovary & $\begin{array}{r}12,38 \\
\pm 0,32\end{array}$ & $\begin{array}{c}10,24 \\
\pm 0,14\end{array}$ & $\begin{array}{r}15,18 \\
\pm 0,54\end{array}$ & $\begin{array}{l}<0,05 \\
<0,05\end{array}$ \\
\hline Primary follicle area, $\times 10^{3} \mu \mathrm{m}^{2}$ & $\begin{array}{c}6838 \\
\pm 11,42 \\
\end{array}$ & $\begin{array}{c}6324 \\
\pm 11,34 \\
\end{array}$ & $\begin{array}{c}7284 \\
\pm 12,82 \\
\end{array}$ & $\begin{array}{l}<0,01 \\
<0,05 \\
\end{array}$ \\
\hline Primary follicle diameter, $\mu \mathrm{m}$ & $\begin{array}{r}89,98 \\
\pm 0,44 \\
\end{array}$ & $\begin{array}{l}87,12 \\
\pm 0,28 \\
\end{array}$ & $\begin{array}{r}92,18 \\
\pm 0,56 \\
\end{array}$ & $\begin{array}{l}<0,05 \\
<0,05\end{array}$ \\
\hline $\begin{array}{l}\text { The number of follicular cells in the follicular layer of the } \\
\text { primary follicle }\end{array}$ & $\begin{array}{r}7,38 \\
\pm 0,22 \\
\end{array}$ & $\begin{array}{r}6,18 \\
\pm 0,28\end{array}$ & $\begin{array}{c}8,34 \\
\pm 0,14 \\
\end{array}$ & $\begin{array}{l}<0,05 \\
<0,05\end{array}$ \\
\hline Number of secondary follicles in the ovary & $\begin{array}{r}9,28 \\
\pm 0,32 \\
\end{array}$ & $\begin{array}{r}7,36 \\
\pm 0,15 \\
\end{array}$ & $\begin{array}{r}11,48 \\
\pm 0,28 \\
\end{array}$ & $\begin{array}{l}<0,05 \\
<0,05\end{array}$ \\
\hline Area of the secondary follicle, $\times 10^{3} \mu \mathrm{m}^{2}$ & $\begin{array}{r}40,12 \\
\pm 0,12\end{array}$ & $\begin{array}{l}38,12 \\
\pm 0,14\end{array}$ & $\begin{array}{r}43,78 \\
\pm 1,18\end{array}$ & $\begin{array}{l}<0,05 \\
<0,05\end{array}$ \\
\hline Diameter of the secondary follicle, $\mu \mathrm{m}$ & $\begin{array}{l}219,76 \\
\pm 3,92 \\
\end{array}$ & $\begin{array}{l}208,16 \\
\pm 1,12 \\
\end{array}$ & $\begin{array}{r}232,28 \\
\pm 1,14 \\
\end{array}$ & $\begin{array}{l}<0,05 \\
<0,05\end{array}$ \\
\hline Number of tertiary follicles in the ovary & $\begin{array}{r}6,38 \\
\pm 0,32 \\
\end{array}$ & $\begin{array}{c}4,26 \\
\pm 0,15\end{array}$ & $\begin{array}{c}8,02 \\
\pm 0,18\end{array}$ & $\begin{array}{l}<0,05 \\
<0,05\end{array}$ \\
\hline Area of the tertiary follicle, $\times 10^{3} \mu \mathrm{m}^{2}$ & $\begin{array}{r}227,65 \\
\pm 1,44\end{array}$ & $\begin{array}{l}182,34 \\
\pm 1,12\end{array}$ & $\begin{array}{l}241,38 \\
\pm 1,86\end{array}$ & $\begin{array}{l}<0,01 \\
<0,05\end{array}$ \\
\hline The diameter of the tertiary follicle, $\mu \mathrm{m}$ & $\begin{array}{l}509,82 \\
\pm 6,32 \\
\end{array}$ & $\begin{array}{l}482,46 \\
\pm 5,82 \\
\end{array}$ & $\begin{array}{l}545,32 \\
\pm 7,24 \\
\end{array}$ & $\begin{array}{l}<0,05 \\
<0,05\end{array}$ \\
\hline Number of atretic follicles in the ovary & $\begin{array}{c}4,82 \\
\pm 0,11 \\
\end{array}$ & $\begin{array}{r}6,52 \\
\pm 0,22 \\
\end{array}$ & $\begin{array}{c}5,37 \\
\pm 0,12 \\
\end{array}$ & $\begin{array}{l}<0,05 \\
<0,05\end{array}$ \\
\hline $\begin{array}{l}\text { The cell area of the connective tissue stroma of the cortical } \\
\qquad \text { layer, } \mu \mathrm{m}^{2}\end{array}$ & $\begin{array}{r}37,32 \\
\pm 1,12\end{array}$ & $\begin{array}{r}32,78 \\
\pm 0,74\end{array}$ & $\begin{array}{l}41,56 \\
\pm 0,88\end{array}$ & $\begin{array}{l}<0,05 \\
<0,05\end{array}$ \\
\hline $\begin{array}{l}\text { Area of cells of the connective tissue stroma in the medullary } \\
\text { layer, } \mu \mathrm{m}^{2}\end{array}$ & $\begin{array}{r}49,33 \\
\pm 1,42 \\
\end{array}$ & $\begin{array}{r}44,16 \\
\pm 0,96 \\
\end{array}$ & $\begin{array}{r}52,62 \\
\pm 1,86 \\
\end{array}$ & $\begin{array}{l}<0,05 \\
>0,05\end{array}$ \\
\hline Number of menstrual yellow bodies in the cortical layer & $\begin{array}{c}6,92 \\
\pm 0,34\end{array}$ & $\begin{array}{c}5,24 \\
\pm 0,18\end{array}$ & $\begin{array}{l}8,12 \\
\pm 0,1\end{array}$ & $\begin{array}{l}<0,05 \\
<0,05\end{array}$ \\
\hline Area of menstrual yellow bodies in the cortical layer, $\mu \mathrm{m}^{2}$ & $\begin{array}{l}339,32 \\
\pm 5,44\end{array}$ & $\begin{array}{l}286,56 \\
\pm 4,24\end{array}$ & $\begin{array}{l}384,42 \\
\pm 6,68\end{array}$ & $\begin{array}{l}<0,05 \\
<0,05\end{array}$ \\
\hline Number of luteal cells of yellow bodies & $\begin{array}{l}176,05 \\
\pm 6,14 \\
\end{array}$ & $\begin{array}{l}146,48 \\
\pm 5,92 \\
\end{array}$ & $\begin{array}{l}218,62 \\
\pm 7,26\end{array}$ & $\begin{array}{l}<0,05 \\
<0,05\end{array}$ \\
\hline The area of luteal cells of yellow bodies, $\mu \mathrm{m}^{2}$ & $\begin{array}{l}1626,39 \\
\pm 54,46\end{array}$ & $\begin{array}{l}1648,32 \\
\pm 48,08\end{array}$ & $\begin{array}{l}1611,86 \\
\pm 71,64\end{array}$ & $\begin{array}{l}>0,05 \\
>0,05\end{array}$ \\
\hline
\end{tabular}

$\mathrm{p}_{1}$ - the reliability of the difference between the animals in the control group and ovarian torsion;

$\mathrm{p}_{2}$ - the reliability of the difference between animals in normal and 1 day after ovarian detorsion.

The obtained tissues were preserved in 10\% aqueous formalin for two days. After the material was preserved, it was dehydrated in a polyhydric alcohol system and then immersed in paraffin blocks. Sections of the preparations 5-7 $\mu \mathrm{m}$ thick were stained with hematoxylin and eosin. The study of colored preparations, their structural study with photo-fixation was performed using Olympus Imaging CORP Model No E - 410 DC 7:4 VD 56547931 morphometric complex at magnification of 100 and 200 times.

\section{RESULTS}

The standard approach was used in all rats: in a condition of anesthesia in live animals, it was obligatory to perform relaparotomy in the conditions indicated by the design of the first stage of the experiment in conditions of a working heart and a self-functioning respiratory system. We performed an examination of the abdominal organs with a visual macroscopic evaluation of changes by the organs of the reproductive system. Macroscopic examination in 
animals 24 hours after the formation of a UA tosion model revealed swelling of the uterine horn, hyperemia, and edema of the oviduct and UA (Fig. 2).

Forty eight after the formation of pathological process model, macroscopically, an increase of the uterine horn edema, the appearance of single sections of venous stasis in the mesovarium vessels and in the uterus, also hyperemia and uterine edema were determined (Fig. 3).

72 hours after the formation of the uterine appendage's torsion model, multiple sections of venous stasis were observed in the vessels of the mesovarium and also in the horn of the uterus, marked hyperemia and edema of the oviduct, areas of hemorrhage in the ovary (Fig. 4).

96 hours after the formation of the UA torsion in the abdominal cavity was determined muddy effusion, widespread sites of venous stasis in the vessels of the uterine horn, marked hyperemia and swelling of the oviduct, multiple foci of hemorrhage in the ovary. In the animals of this group, the oviducts and UA had a purple color and were difficult to differentiate from each other and from the surrounding tissues due to massive edema, multiple hemorrhages (Fig. 5).

A comprehensive assessment of the morphological changes in the PM of experimental animals was performed taking into account three main features: necrosis of the ovarian parenchyma; circulatory disorders; expressiveness of inflammation.

In the morphological study of changes in UA of experimental animals after their one-day torsion, mainly parenchymatous phenomena were determined: the increasing of plethora in blood vessels of the ovarium and surrounding tissues. The plethora of venous vessels was widespread, but without deformation of the walls of the vessels and excessive dilatation of their lumen. In the stroma and in the ovarian follicles, necrosis sites were absent in all fields of view. In the connective tissue surrounding the appendages of the uterus, a slight accumulation of perivascular exudate was formed, consisting mainly of single segmented neutrophils and erythrocytes against a background of moderate perivascular edema. These changes corresponded to an acute stage of serous inflammation. Taking into account the foci and localization, the degree of their expressiveness during this period of experiment can be regarded as minimally expressed (Fig. 6).

Morphological changes in the group of experimental animals with a two-day torsion of the UA leading histological factors of the pathological condition were signs of acute circulatory disorders. Unlike the previous group of animals with one-day ovarian torsion, this period was characterized by the presence of single perivasal hemorrhages, a more pronounced deformation of the vessels due to their large plethora, which persisted. Ознаки некрозу в гістологічних препаратах даної серії були відсутні, як в яєчниках, так і в оточуючих тканинах. In addition, the accumulation of segmented neutrophils with the inclusion of a small number of monocytes and erythrocytes was observed in these laboratory preparations (Fig. 7).

In a series of preparations of experimental animals with a three-day torsion of the uterine appendages, signs of diffuse persistent blood flow disturbance were determined morphologically. The veins and arteries had a curvilinear direction, deformed contours and unevenly dilated lumen. Unlike previous periods of the UA torsion, the vessels' plethora had a more pronounced character directly in the ovarian parenchyma, which in our opinion testified to the increasing decompensation by the vaso-motor response of the organism in the form of widespread signs of circulatory disorders. In this time period, the signs of necrosis in the primary follicles were morphologically determined. No signs of necrosis in the secondary and tertiary follicles were observed. The character of inflammatory signs is progressively worsened by increasing tissue damage and active migration of peripheral blood monocytes. These monocytes were transformed into tissue macrophages. (Fig. 8).

In histological preparations of experimental animals after four days of perversion of the uterine appendages, edema of the stroma was determined around the ovarian vessels, moderate coagulation necrosis of the focal character, which had no spread to the surrounding parenchyma. Moderately focal dystrophic changes were observed, in the form of karyopyknosis and karyorrexis in cells, in areas adjacent to areas of brain necrosis. Follicle cells had no structural alterations and no signs of necrosis. Most vessels acquired a paretic enlargement, there was a stratification of the blood level in their lumen into the fluid component and the blood elements. Significant areas of mild lympho-monocytic infiltration of the capsule of some ovaries were identified, which may indicate the spread of processes to the serous membranes of the abdominal cavity (Fig. 9).

The results of the studies have convincingly shown that impaired blood circulation in the UA leads to the development of gradual pathological changes in them, the intensity of which increases in proportion to the duration of the torsion. After detorsion and restoration of blood flow, morphological changes in the ovaries do not undergo irreversible necrotic changes and maintain their functional state. The degree of impaired blood flow directly depends on the duration and stiffness (degree) of the torsion. In the process of conducting morphological and morphometric studies in experimental modeling of uterine torsion in females of rats, it was found that the limiting period of preservation of histological integrity of the gonads was 3 days ( 72 hours).

The data obtained in the experiment showed that there was a discrepancy between the macroscopic features of the twisted uterine appendages and the microscopic changes in their morphological examination. Despite the presence of external signs of significant disorders such as the development of necrosis in the tissue of the uterine appendages, after the detorsion and restoration of blood flow in them, studies have shown the possibility of performing organ-saving surgical interventions in the torsion of the uterine appendages.

Taking into account the data of the previous section of experimental studies, which determined the limiting period of preservation of histological integrity of the gonads within 72 hours since the formation of the torsion, we have 
studied the peculiarities of the morphological structure of the ovaries in rats based on the morphometric evaluation of their structural components of cortical and medullar substances after torsion and after detorsion in similar terms (Table II).

As histological signs of follicular atresia, the average number of generative elements of the ovaries were examined: pycnotization of follicular cells and teocytes; the presence of apoptotic bodies and / or cellular detritus at the periphery of the antrum; detachment of follicular cells from the basement membrane; atretic follicles were characterized by thinning of the granular layer of cells; the presence of macrophages in the antrum of the follicle; hypertrophy of the layer of thecocytes; degenerative changes in the oocyte.

The gradual thinning of the follicular epithelium reflected the progression of atresia from early to late stages. After one day of ovarian torsion, the initial phenomena of follicle atresia with more active involvement of the primary follicles were noted. In the second and third days after UA torsion, the process of follicular atresia progressed rapidly. The rats of the experimental groups (after torsion and agter detorsion) had a number of morphological changes in the ovary of varying degrees of severity, depending on the time of torsion.

At all periods of torsion and after detorsion of uterine appendages in rats, the ovaries were covered with cubic epithelium, height of which was smaller after torsion (average value $7.84 \pm 0.1 \mu \mathrm{m}$ ) than normal (average value $8.22 \pm 0.11 \mu \mathrm{m}$ ) and bigger after the detorsion (average value $9.68 \pm 0.22 \mu \mathrm{m})(\mathrm{p}<0.05)$ than in the animals of the control group due to its proliferation process. After torsion and after detrosion of uterine appendages, microvilli on the surface of the epithelium were partially reduced. The tunica albuginea in animals with the torsion was thicker due to edema and stratification of fibrous fibers and was $21.16 \pm$ $0.59 \mu \mathrm{m}$ compared with the control $-19.18 \pm 0.41 \mu \mathrm{m}$, after elimination of the torsion the tunica albuginea thickness was smaller than in control group and was $17.24 \pm 0.38$ $\mu \mathrm{m}(\mathrm{p}<0.05)$.

We observed a decrease in the diameter of the blood vessels that penetrate the ovarian medulla at 3 days perversion compared to the control by $27.55 \%$ ( $8.94 \pm 0.76 \mu \mathrm{m}$ versus $12.34 \pm 1.05 \mu \mathrm{m}(\mathrm{p}<0,05))$. There was also an increase in the value of the indicator by $40.84 \%$ after its detorsion $(17.38 \pm 1.46 \mu \mathrm{m}$ against $12.34 \pm 1.05 \mu \mathrm{m}(\mathrm{p}<0.05))$.

We also observed an increase in cross-sectional area with ovarian torsion, thickness and area of the cortex and medullary layer in comparison with the control group, beside this decrease in the values of the described morphological factors after detrosion indicate the reversibility of changes in microcirculatory disorders, including edema, in these experiments.

After analyzing the ovarian follicular apparatus, we can say that in the experimental groups of animals compared with the control, there were certain quantitative and qualitative changes in the structural components of the gonads.

On the 1st day of the experiment, the follicles of varying degrees of maturity with oval or irregular shape were contained in the ovarian cortex in rats with twisated gonads. Compared with the norm, most of the follicles at this period of the experiment were in the initial and later stages of atresia, more pronounced phenomena of involution were determined in the histological structure and morphometric indices of the secondary and tertiary follicles. On the second and third days of torsion, there was a further progression of follicular degeneration with replacement of the primordial follicles with connective tissue, as evidenced by their rare location and sometimes by the location of irregular groups. The regression of primary follicles occurred through the formation of atretic bodies. Atresia of the secondary and tertiary follicles was due to the passage of the stage of the atretic body, followed by replacement of its interstitial cells, and later fibrous tissue with its hyalinosis. Such changes make it possible to conclude that there is a clear decrease in the total content of follicles and the predominance of yellow and atretic bodies in the parenchyma of the ovary after its perversion (Table III).

Thus, the number of primordial follicles in the ovary after 3 days of torsion decreased by $3.92 \%$ compared to the norm, respectively 7,84 $\pm 0,12$ against $8,16 \pm 0,16$ (p> $0,05)$, and after detorsion increased by $14.96 \%$, respectively $9.38 \pm 0.22$ versus $8.16 \pm 0.16(\mathrm{p}<0.05)$. In addition, the area of the primordial follicles after torsion increased by 9.13\% compared to normal, respectively $21.16 \pm 0.39 \times$ $103 \mu \mathrm{m}^{2}$ against $19.39 \pm 0.28 \times 103 \mu \mathrm{m}^{2}(\mathrm{p}<0.05)$, and after of the detorsion was below the control by $5.93 \%$, respectively $18.24 \pm 0.16 \times 103 \mu \mathrm{m}^{2}$ versus $19.39 \pm 0.28 \times$ $103 \mu \mathrm{m}^{2}(\mathrm{p}<0.05)$.

The diameter of the primordial follicles after the torsion of the UA increased by $10.72 \%$ compared to the control, respectively, $10368 \pm 22.59 \mu \mathrm{m}$ against $9364 \pm 19.42 \mu \mathrm{m}$ ( $\mathrm{p}<0.01$ ), and after detorsion by $7.33 \%$ was lower, than normal value, respectively $8678 \pm 18.52 \mu \mathrm{m}$ vs $9364 \pm$ $19.42 \mu \mathrm{m}(\mathrm{p}<0.01)$.

At all times of perversion, signs of oocyte degeneration cytoplasm swelling, hypochromia, homogenization, or vacuolation of the cytoplasm, in some cases, even cell destruction, were observed in more mature follicles. All these signs indicated the initial (at the 1st day of the experiment) and deeper (at the II and III days) processes of atresia. Thus, the number of atretic follicles in the ovary at torsion was $6.52 \pm 0.22$, after detorsion $-5.37 \pm 0.12$, in the control group $-4.82 \pm 0.11(\mathrm{p}<0.05)$.

Also, in the ovaries of experimental animals, follicular cysts of different sizes (cystic atresia of the follicles) were determined during its perversion. Depending on the phase of the cycle, the inner lining of the cyst was represented by several layers of follicular cells, and in some cases, the inner lining of the cyst was absent and the capsule was represented only by fibrous tissue.

The number of primary follicles, their area, diameter and the number of follicular cells in the follicular layer of the primary follicle, when the uterine appendage was twisted, decreased by $7.29 \%, 7.52 \%, 3.18 \%, 16.26$, respectively. And after the detorsion, there was an increase of $22.62 \%, 6.52 \%$, $2.44 \%, 13.01 \%(\mathrm{p}<0.05)$ relative to the norm. 
The number of secondary follicles in the ovary and their area after torsion decreased by $20.69 \%$ and $4.99 \%$, respectively, and after the detorsion, the indices increased by $23.71 \%$ and $9.12 \%$, respectively ( $\mathrm{p}<0.05)$.

One day after the detrusion, the degenerative changes of the maturing follicles were significantly smaller compared to those in the gonadal torsion: the diameter of the secondary follicle after the torsion was $208.16 \pm 1.22 \mu \mathrm{m}$, after the detorsion was $232.28 \pm 1.14 \mu \mathrm{m}$, in control group $219.76 \pm 3.92 \mu \mathrm{m}$. The diameter of the tertiary follicle in the twisted UA averaged $482.46 \pm 5.82 \mu \mathrm{m}$, after the detorsion $-545.32 \pm 7.24 \mu \mathrm{m}$, in the control group $-509.82 \pm$ $6.32 \mu \mathrm{m}(\mathrm{p}<0.05)$.

The number of tertiary follicles in the ovary and their area after torsion decreased by $33.23 \%, 19.9 \%$, respectively, and increased after the detorsion by $25.71 \%$ and $6.03 \%$ $(\mathrm{p}<0.05)$.

One day after the elimination of the pervert, the morphology of the yellow bodies was characterized by an increase in their vascularization and an increase in the size of luteal cells, and, accordingly, an increase in the size of the yellow body itself, compared to the previous study group in the same term, in which the yellow bodies gradually degenerated. In the case of ovarian overturning, the yellow bodies were characterized by the so-called dystrophic polymorphism: oval and irregular structures (in the control group - round) were encountered, their size fluctuated greatly and conceded to the control group at all study periods. Also, the yellow bodies had a clearer outline due to the activation and hyperplasia of the fibroblasts of the fibrous membrane. The histological features of the structure of the yellow bodies were a more loose arrangement of luteinocytes, their size and area decreased, as evidenced by the data in the table. Degenerative-dystrophic changes of luteinocytes were also manifested in the form of an increase in nuclear-cytoplasmic index and moderate vacuolation of the cytoplasm. The decrease in the density of luteinocytes in yellow bodies can also be explained by edema of the fibrous stroma of the organ. In the appendages of the uterus, after their torsion on the 2nd and especially the 3rd day of the experiment, yellow bodies were also identified, in the center of which the areas of stellar necrosis were revealed.

The number and area of menstrual yellow bodies in the cortical layer after torsion decreased by $24.28 \%$ and $15.55 \%$, respectively, and after detorsions exceeded the normal values by $15.9 \%$ and $13.29 \%$, respectively, $(\mathrm{p}<0.05)$.

The number of yellow lutein cells after the torsion was $16.8 \%$ less than normal and after the detorsion was $24.18 \%$ more than in the control group $(\mathrm{p}<0.05)$. The area of yellow luteal cells differed slightly in the comparison groups. After the torsion, the increase in the index value was only $1.3 \%$, and after the detorsion its level was $0.9 \%$ lower than the indicator of the control group ( $\mathrm{p}>0.05$ ).

The stroma of the cortical substance of the ovaries between the follicles and the yellow bodies of the ovaries was represented by layers of fibrous tissue and interstitial cells that had a fusiform shape. The stroma of the medullary substance was represented by a fibrous fibrous tissue.
The cell surface of the connective tissue stroma of the cortical layer was, on average, $37.32 \pm 1.12 \mu \mathrm{m}^{2}$ : after the torsion $-32.78 \pm 0.74 \mu \mathrm{m}^{2}$, after the detorsion $-41.56 \pm$ $0.88 \mu \mathrm{m}^{2}(\mathrm{p}<0.05)$. The area of cells of the connective tissue stroma of the medullary layer was normally $49.33 \pm 1.42$ $\mu \mathrm{m}^{2}$, after torsion $-44.16 \pm 0.96 \mu \mathrm{m}^{2}(\mathrm{p}<0.05)$, and after detorsion $-52.62 \pm 1.86 \mu \mathrm{m}^{2}(\mathrm{p}>0.05)$.

One day after the uterine appendage was disturbed, leukostasis was determined in vessels with single leukocyte output outside the vessels, inflammatory changes developed on the 2nd and 3rd days -microfoci of leukocyte infiltration of medullary and cortical tissues, yellow bodies.

Against the background of the decrease in the volume of yellow bodies, the restructuring of their vascular network was observed. Circulatory disorders were manifested in the form of congestive plethora of the capillary-venous component of vessels of larger caliber and vessels of hemomicrocirculatory network of varying degrees of expression with the phenomenon of erythrocyte adhesion in some capillaries up to their thrombosis. Part of the vessels were bloodless and optically empty. Perivascular edema was also identified as a sign of haemorrhage disorder.

Thus, after distortion of the uterine appendages, along with the degenerative-dystrophic phenomena of the vascular network, degenerative-dystrophic changes of luteinocytes occurred. The stroma of the cortical and medullary substances of the ovaries in experimental ovarian torsion, already on the 1st day was characterized by a loose arrangement of connective tissue fibers due to its swelling. On the third day of the experiment, deeper disorganization and thickening of the fibrous component of the stroma occurred. Also, in this period, there were more significant hemodynamic changes in the form of stasis, perivascular edema, paretic expansion of the vessels, which were especially pronounced in the medullary substance of the ovaries. Thus, there was a progression of ovarian parenchyma hypoxia. There was a change in the ratio of cortical and medullary substances compared to control due to an increase of thw medullary substances volume mainly due to stromal edema and decrease of the cortical substance as a result of progressive atresia of the follicular apparatus and a decrease in the size of the yellow bodies (1: 4 after the torsion, versus 1:3.5 after the detorsion and 1: 3 in normal cases).

\section{DISCUSSION}

Summarizing this section, which relates to experimental studies, it can be considered proven that the torsion of UA in female rats leads to accelerated and active atresia of the follicles, which in turn contributes to the reduction of the total number of follicles in the ovaries, reduce the size of yellow bodies, reduction of the luteocytes content, the expansion of the stroma of the organ against the background of hemodynamic disorders that contribute to the deepening of the altering effect on all structures of UA, resulting in the appearance of disorders of folliculogenesis, enhancing atretic processes resulting in a decrease in the reproductive potential of the ovary. 
After ovarian detorsion, until 72 hours after its torsion, reliable reversible restoration of the structural components of the ovary is determined as a positive consequence of the effect of the correction factor (detorsion).

Pathomorphological changes in the experimental torsion of the UA [12] in the first hours consisted in violation of hemodynamics, which was manifested by the venous plethora in the cortical and medullary layers. In the vessels, the phenomena of stasis of blood elements (erythrostasis, marginal standing of leukocytes) were observed. Disorders of hemodynamics and exudative processes, an increase in the volume of the venous network are most pronounced in the early stages of ovarian torsion. Torsion of the uterine appendages was accompanied by damage to the plexuses of the blood and lymphatic vessels of the mesovarium, followed by impaired ovarian tissue perfusion. Partial occlusion of blood vessels supplying the ovary leads to a decrease in the number of primordial and maturing follicles, yellow bodies and the development of degenerative changes in the preserved follicles.

\section{CONCLUSIONS}

The data obtained showed that the gonads of female respond to torsion with structural changes that may lead to a decrease in reproductive capacity. Up to 72 hours, the ovaries respond to direct damage by short-term activation of follicle growth processes, followed by the development of atretic processes, a decrease in the number of generative elements, temporary depletion of the compensatory mechanisms of the ovary, with the subsequent complete restoration of all structural components of the organ. In research practice, it is possible to recommend the use of an experimental model of ovarian torsion in female rats to investigate the effectiveness of the impact and timing of corrective factors on the restorative course of morphological, structural and functional properties of the organ.

\section{REFERENCES}

1. Bolli P., Schädelin S., Holland-Cunz S. et al. Ovarian torsion in children: Development of a predictive score. Medicine (Baltimore). 2017;96(43):82-99.

2. Huang C., Hong M.K., Ding D.C.A review of ovary torsion. 2017;29(3):143147.

3. Demir M., Barut M.U., Ağar M. et al. Isolated torsion of a tubal ectopic pregnancy: must be kept in mind. International J of Health Services Research and Policy. 2017;2(1):10-13.

4. Güney C., Coskun A. A Fifteen-Year Analysis of Rare Isolated Fallopian Tube Torsions in Adolescent Children: A Case Series. Diagnostics. 2019;9(110):1-8.

5. Hayward L.M., Sellheim D., Scholl J. et al. Reflection on Nancy T. Watts' Division of Physical Therapist and Physical Therapist Assistant Responsibility in Clinical Practice: Future Directions. Physical Therapy. 2019;99(10):1272-1277.
6. Yıldırım Ş., Topaloğlu N., Tekin M. et al. Protective role of proanthocyanidin in experimental ovarian torsion. Med J Islam Repub Iran. 2015;23(29):185.

7. Di Saverio S., Birindelli A., Kelly M.D. et al. WSES Jerusalem guidelines for diagnosis and treatment of acute appendicitis. World Journal of Emergency Surgery. 2016;11(34):1-25.

8. Park J.Y., Her K., Kim B.S. et al. A completely isolated intestinal duplication cyst mimicking ovarian cyst torsion in an adult. World J Gastroenterol. 2014;20(2):603-606.

9. Mutiso S.K., Oindi F.M. Pediatric ovarian torsion in a nine-year-old girl: A twisted tale of pain. Int J Case Rep Images. 2017;8(5):348-351.

10. Mandade K., Yadav V., Singh S. et al. Bilateral Parovarian Cyst Complicated with Torsion In 12yrs Girl: Case Report. IOSR Journal of Dental and Medical Sciences. 2014;13(1):89-91.

11. Breech L.L., Hillard P.J. Adnexal torsion in pediatric and adolescent girls. Curr Opin Obstet Gynecol. 2005;17(5):483-489.

12. Emonts M., Doornewaard H., Admiraal J.C. Adnexal torsion in very young girls: diagnostic pitfalls. Eur J Obstet Gynecol Reprod Biol. 2004;116(2):207-210.

13. Li C., Wang S., Tao X. et al. Torsion of normal-sized ovary during late pregnancy: A case report and review of the literature. J Obstet Gynaecol Res. 2018;44(11):2110-2114.

This work is the part of target scientific work "The development and improvement of the modern technology of the diagnostics, treatment, prevention and rehabilitation in the pediatric surgery" which was made by the pediatric surgical department (state registration $N$ 0118U003918).

\section{ORCID and contributionship:}

Viktor S. Konoplitskyi: 0000-0001-9525-1547 A,D,E,F

Yurii Ye. Korobko: 0000-0002-3299-878X B,C,F

\section{Conflict of interest:}

The Authors declare no conflict of interest.

\section{CORRESPONDING AUTHOR Yurii Ye. Korobko \\ National Pirogov Memorial Medical University \\ 56 Pirogov st., 21018 Vinnytsia, Ukraine \\ tel: +380634369982 \\ e-mail: lundqist747@gmail.com}

Received: 24.06 .2020

Accepted:02.06.2021
A - Work concept and design, B - Data collection and analysis, C - Responsibility for statistical analysis, D-Writing the article, $\mathbf{E}$ - Critical review, $\mathbf{F}$ - Final approval of the article 